\title{
Computer Games Influence on Everyday Social Practices of Students-Gamers
}

\author{
Rimma R. Khanmurzina \\ Kazan Innovative University named after V. G. Timiryasov, Russia \\ ORCID: 0000-0001-5912-8349 \\ Elena I. Cherdymova \\ Samara National Research University named after academician S.P. Korolev (Samara \\ University), Russia \\ ORCID: 0000-0002-0392-8483 \\ Tatyana Yu. Guryanova \\ Chuvash State University named after I.N. Ulyanov, Russia \\ ORCID: 0000-0003-3440-4479 \\ Rita A. Toriia \\ Financial University under the Government of the Russian Federation, Russia \\ ORCID: 0000-0002-2273-1926 \\ Evgenia M. Sukhodolova \\ Gzhel State University, Russia \\ ORCID: 0000-0003-3025-7432 \\ Larisa I. Tararina \\ Russian State Social University, Russia \\ ORCID: 0000-0002-0280-135X
}

\begin{abstract}
The article considers one of the new social phenomena that have arisen in society, and is currently changing everyday social practices, which are one of the integral parts of the new media - computer games. The problem of the study is conditioned by the fact that computer games are gaining popularity, while increasingly influencing players, changing their established way of life, behaviors, forming new styles of communication and attitude to the surrounding reality. The activation of interest in the process of everyday social practices arose due to the shift of value orientations in the structure of students' lifestyle. The aim of the study is to analyze the impact of computer games on everyday social practices of students-gamers. The leading methods for the study of this problem is the interview method, which allows revealing more fully and multifaceted impact of computer games on everyday social practices of students-gamers. It was found that the main characteristics of the gamer are: the ability to appreciate the game; the ability to play a lot of fun, not to chase the game awards; to see in the games something of great importance; to know a lot about different games; to be able to play well and understand the game. It is shown that computer games do not generate subcultures, but only try to unite people and teach them to work together in a team. Gamers arrange events for any particular game they play. Such meetings are most often of a competitive nature. Students gamers note the following skills that they acquire through the games: meeting new people; learning English; improving
\end{abstract}


communication skills; interesting stories; historical moments; military Affairs (weapons, equipment, military battles, etc.); myths and legends of different world cultures. The practical significance lies in the fact that the data obtained in the work can be used in social psychology, age psychology, psychology of work, sociology, as well as for further theoretical development of this issue.

Keywords: students, computer games, gamers, social practices

\section{INTRODUCTION}

For the new digital generation, computer games are becoming a part of everyday social reality. This kind of fact could not be left without due attention by researchers of different spheres of scientific activity. Many psychologists, cultural scientists, philosophers and sociologists are studying the impact of computer games on computer players (gamers), plunging into the investigated field deeper. The 2000s were the decade in which the changes affected not only our audience perception of games, but also how the gameplay itself was worked out. Multiplayer online games and access technology to them, providing a way to access the joint game over the Internet, pointed to the further trajectory of the games, where the game over the Internet has become a major focus.

Over its forty-year history of computer games in recent years, they are gaining increasing popularity. First of all, this is due to the fact that in 2011 the USA government and the American national Foundation for the arts officially recognized computer games as an art form along with cinema, music, painting, literature, etc., and in many Western countries, eSports tournaments are held annually (Savchuk, 2014).

Young people, mostly the audience of the gaming industry, are immersing in new virtual spaces, where there are their own norms and rules of conduct. The amount of research conducted in the field of studying the impact of computer games on young people, proves the importance and significance of this area of scientific interests. For example, psychologists say that the virtual computer world, which is mostly hostile to the player, provokes him to an aggressive confrontation with this world. Thus, games teach a gamer to model the behavior of attack and defense. At the same time for following these rules, the player receives bonuses and incentives from the game, which also serve as levers motivating to further gameplay (Borytko, 2002; Buglak, 2013; Cherdymova et al., 2019; Korneeva, 2004; Shlimovich, 1998). The impact of computer games on the everyday social practices of gamers is great. They become an integral part of the gamer's life, which can transfer elements of the game model of behavior into real life. In order to understand who gamers are and what impact computer games can have on them, you need to first consider the concept of everyday social practices (Fomicheva, Shmelev \& Burmistrov, 1991; Pleshakov \& Namestnikov, 2013; Shapkin, 1999; Volkov, 1997).

According to Zborovsky's (2007) definition, social everyday practices are understood as the lifestyle, features and characteristic features of each person's behavior, both in everyday life and in its specific situations. In continuation of this idea, Shugalsky (2012) writes that practices determine the way of thinking and behavior in accordance with the indicators of accessible and inaccessible (that for us and not for us), thereby forcing social actors to adapt to the present and future.

It follows from this that social practices are fickle and changeable, thus becoming the subject of the study of social processes. Individuals, performing appropriate actions, are able to change and transform the social space around them. This applies to both long-term practices of behavior 
and every day, habitual, ordinary actions that do not require explanation and often seem insignificant, ordinary or simply illogical (Butenko, 2001; Cherdymova et al., 2018; Dobrenkov \& Kravchenko, 2001; Korbut, 2009; Reznick, 2008).

For the emergence of any social practice, it is natural to have their own characteristics, based on the causes and prerequisites. We cannot always correctly predict the motives of the action, but we can always say that social practices are unique in their structure depending on the manner and implementation of their execution.

Therefore, social practices can be social behavior based on everyday ordinary knowledge and have sacred, unconscious experience. Anthropological philosopher focuses on the fact that practice is the whole set of produced actions, but it is not noticed either because of unproblematic nature, or considering it an external manifestation of something hidden behind it - consciousness, thinking, cognitive processes, etc. (Wittgenstein, 1994). The problematic situation of practices in real life arises only when they are born based on new, non-standard situations. Usually, the subject of social processes acts out of habit, automatically, but if the subject of interaction somehow changes, it immediately becomes the object of human attention.

Social practices in the sociological approach are revealed by three parameters: a set of accepted in the culture (traditional) ways of activity, skills of handling various objects; thinking or action out of habit, following the rule, behavior that has a ritual character; private social institutions (Boleskina, 2002; Cherevko, 2010; Gutman, 2009; Karpenko, 2005; Parking, 2015). Taking into account all the explanations of everyday practices, we conclude that any action committed by an individual in society, acquires the meaning of social.

Social practices are a process of actions that is spatially and temporally contextual and ensures the unity of subjective and objective aspects (Alisov et al., 2018; Cherdymova et al., 2018, 2019; Sorokoumova et al., 2019). Therefore, if the social action is repeated repeatedly and has natural features, it receives a criterion and classification in the structure of habitus, acquiring the status of the usual, every day. Thus becoming a daily practice of social behavior.

\section{MATERIALS AND METHODS}

The focus of research has shifted to the students-gamers. The object was young people aged 18 to 25 years. The decision to take for the object of study of respondents the student youth was due to the fact that this group has a socio-psychological maturity and the ability to analyze their activities more deeply and in more detail - in contrast to the adolescent.

The criteria for the selection of respondents were:

- Student youth;

- Self-identification of the student himself as a computer player-gamer;

- Frequency of stay in the game space (from daily to two or three times a week).

Students have self-reflection, allowing them to analyze their actions and the results of decisions, including gameplay.

The player's weekly stay in the game space (from daily to twice a week) is able to tell us that computer games are an integral part of his/her daily reality and part of his/her lifestyle. 
At the same time, casual games with which gamers can interact were excluded from the list of games. Casual computer games are gaming programs designed for an unlimited number of Internet users. These are simple games in their content and do not require special game mechanics. Casual games usually have a small size: from five to $50 \mathrm{MB}$, which allows them to be an application to the operating system of the computer or installed on the platform of social networks. These games are played on a case-by-case basis and include all sorts of game genres. We considered it necessary to exclude this type of games from the criteria for the selection of gamers, because these games are played on a case-by-case basis and their goal is the time waste. They do not involve large time-consuming. One of these games are games: Klondike, Checkers, Three in a row and many others.

The games that gamers play are the complete opposite of casual. They include the plot, the heavy weight of the game program (sometimes-reaching up to $50 \mathrm{~GB}$ ), due to the high requirements for gameplay, and high requirements for components of the computer. This applies to both single-player games and online (network) games.

Research tasks:

- To identify the degree of involvement of students-gamers in computer games.

- To analyze the influence of social environment (reference groups) on the involvement of students in gaming.

- To establish the impact of computer games on social skills and behavior models of studentsgamers?

The study was conducted in four stages.

The first stage was a theoretical acquaintance with the community of computer players. In addition, there was a need to compile a dictionary of terms, words and expressions most often used by gamers that helped the interviewer to better understand the respondents.

At the second stage, an interview guide with computer players was compiled. This allowed us to expand our understanding of the students-gamers and the specifics of the subject we are studying. Based on these interviews, the tool for interviewing experts was adjusted.

The third stage was the collection of primary information and its processing.

The fourth and final stage was based on the interpretation of the data obtained in accordance with the objectives and to deduce based on them the results of our research.

\section{RESULTS}

During the interviewing of students-gamers, there were a number of problematic issues. First, it should be noted that there were difficulties in finding students as gamers. There was a slang barrier in the understanding of the Central term of the study - gamer. Potential respondentsgamers do not call themselves by this term, using the more familiar to them the word computer player. Secondly, there is a slang barrier. Namely, the frequent use of terms that are intended for inside the game space. Although, despite this, during the interview, the number of such words and expressions, as a rule, was minimized by students.

A completely new phenomenon for the researchers was the use by students of a number of slang words and expressions characteristic of the gamer's vocabulary, as well as emphasizing their belonging to this community and enthusiasm for this type of activity, but not contributing 
to a clear, specific and complete perception of the information received by the researchers. A favorable moment for the researchers was the presence of a positive attitude of respondents and experts to a given research topic. As it became known during the interview, students-gamers play both online and in single-player games, almost in equal degree. For this reason, it is almost impossible to determine which games affect gamers' everyday social practices. Each of the gamers noted that he played computer games from daily stay up to 2-3 times a week: respondents reported that they played daily (7\%); every other day (2\%).

At the same time, $13 \%$ of respondents, mainly those players who spend their time in the game world every day and partially every other day, claim that they can play for 3-4 hours in one day. Five percent of gamer students can spend five or more hours a day in the game space. Only $2 \%$ assured that they play no more than two hours a day, arguing their answer temporary by lack of time, but they play every day. It is impossible to become a gamer overnight. To understand that the game lover becomes a gamer, you can only after a few years. This is how students mark their age at which they started playing computer games - when they were 4-6 years old, or when they were in primary school.

All respondents call themselves gamers, but the wording of the answers to the question "Who are gamers?" always were different. Therefore, it was possible that the main characteristics for the gamer are what he should: be able to appreciate the game; have a lot of fun to play, not to chase the game awards; see in the games something of great importance; know a lot about different games; be able to play well and understand the game.

Students -gamers form both virtual and real communities. According to respondents, virtual communities are formed only based on online games. The means of communication in online games is a game chat and programs that support voice communication. Respondents note that, getting acquainted with other players in an online game, they have "a lot of friends in real and virtual life", and the subject of conversation can be not only a discussion of the gameplay, but also any other topic that affects players: "we communicate absolutely on all topics that concern us, while spending time playing"; "Communicate every day, discuss: politics, society, music, series, events in each other's life and of course the game."

Virtual space teaches gamers to be united and help each other in reality: "the Game is a game; I propose to open only to those who I really trust, and therefore meet. I communicate often, they became for me those who can listen and support morally, unlike a family". As it turned out, computer games do not generate subcultures, but only try to unite people and teach them to work together in a team. Gamer students arrange activities for any particular game they play. Such meetings are most often of a competitive nature. Trying to expand the circle of communication in their interests through such activities.

The gaming real community of gamer students is now beginning to develop more actively in real space. This is most often due to the removal of esports to a more popular level in society.

According to the information received from the students-gamers, communities break up because: the interest in the game is lost; not enough time in reality. There are many barriers for gamers to communicate in reality "...Everyone is busy with their own Affairs and concerns." Students-gamers do not have enough communication, network games help players to get closer: "...I prefer to argue and discuss different topics, learn a lot, "feel that I am not alone" - helps to feel needed, meaningful, useful. Hobbies can affect a person, but not games." 
Through the Internet, it is easier to look for friends with the same interests: "Already directly in the game I'm looking for friends for myself, and if it's nice to communicate with a person, you can meet him/her in reality."

At the same time, there is another aspect: "If you do not know how to communicate in reality, it does not mean that you will become a good interlocutor in the game. The game is a part of real life, it only requires less conditions."

Students gamers are attracted to computer games by the following aspects: the plot (history of the universe); the atmosphere in the game; interactivity; colorful characters; freedom of action; anonymity; openness; the acquisition of gaming experience; the ability to play other roles; interesting spending of time; interesting quests (in-game tasks); beautiful graphics; competition; possibility to learn to communicate.

For most respondents, computer games are a means of recreation, pleasant pastime on a par with movies and books: "...rest from reality, they allow themselves to feel freer, more sociable, share with friends on the game their new experiences".

Almost all gamers have ever dreamed to learn how to create computer games (write scripts or music to them and study the simulation of virtual space): "of Course! I still do not cease to invent their characters, in the hope that someday the designers of gaming companies will notice them and buy the license to the right (enthusiastically and confidently). However, in the end, most concluded that "a long time ago, but later abandoned this idea" and it is not feasible desires. For gamers, this is only a dream, because they cannot find application in real life such skills and the lack of motivation affects.

Only $53 \%$ of respondents from the entire sample confirmed that they used gaming slang outside the game space and quote characters. Of them, five used elements of attributes. It is worth noting that $85 \%$ of these students were girls: "Yes, I constantly quote phrases from games, gesture and copy their facial expressions, as well as elements of appearance and attributes.

Computer games are not only a pleasant pastime for gamers, but also help to learn something new. Student gamers note the following skills that they acquire through the games: meeting new people; learning English; improving communication skills; know interesting stories; learn historical moments; learn military Affairs (weapons, equipment, military battles, etc.); know myths and legends of different world cultures.

Seventy-five percent of gamer students noticed that computer games had a big impact on their daily routine. Only if you go to bed very late. Nevertheless, its change in attitude to real life noted only $12 \%$ of students, which again were girls.

\section{DISCUSSIONS}

We concluded that for a gamer student computer games become a part of everyday reality. The world of computer games is very large and diverse, forcing painstakingly, continuously to be acquainted with all the nuances, rules, and patterns of behavior. In addition, it takes quite a lot of time. Therefore, to become a gamer you need to get involved in games from an early age, when you have most of your free time. Only then, a person is aware of him/herself as a gamer, when his/her gameplay smoothly flows from the amount of time spent into the quality and skill of the game.

Gamer enters into adult student life and he/she does not have as much time to devote to games as before. 
Excessive enthusiasm for computer games at an early age sometimes contributes to the alienation of the gamer from the real social world, which can greatly disturb the parents, but at the same time, the parents themselves or close circle becomes the initiator of the child's introduction to the gameplay.

Often, the student-gamer can have enough emotions from communication in the gaming space because other invisible interlocutors share common interests. However, thanks to the common interest, these same virtual communities of gamers can become a very real practice when real tournaments are held for a certain game, or when players manage to find real communication, bypassing such important reasons as: the geographical remoteness of players from each other and the lack of free time.

Computer games help students-gamers to learn to appreciate the friendship and support of friends, learn a lot and get away from the daily routine, feeling in a new, interesting role.

Gamers often possible to distinguish on the game slang. However, this is not always the case, because in youth people are less trying to differ from other people in the same society.

\section{CONCLUSION}

The impact that computer games have on the everyday social practices of gamers, are reflected by the players themselves only if they began to get acquainted with the games in adolescence. Most of the respondents do not notice this, because they started playing from an early age (410 years) and games have become part of their daily reality. Most often at the beginning of the game, they can greatly affect the novice player, especially at an early age. Gamers note that they are attracted to the colorful world of games, the ability to communicate freely, to try out another new role and become successful by winning the game or earning some insignia for your game character.

Online games contribute to the manifestation of communication skills in reality. Participants of online games try to transfer their virtual communities from the game space to the real world. If the experts noted that the main reason for the emergence of gaming communities in reality is the reason for meeting with like-minded people in the game, the gamers themselves are placing more emphasis on the competitive aspect.

Game-addiction is a major and particularly important negative consequence of gaming activities. The players have a substitute for the real world on the virtual with all its rules and regulations. All socialization comes to naught, because of what the players fall out of society as a person. Experts advise parents of such children to understand the reasons for their stay in the gaming space, and then understand what the virtual world is more attractive present.

Student gamers note that computer games still have a positive impact on players, helping them to develop self-reflection, develop communication skills and master the speed of reaction. Of the negative experts, note the departure from reality or the manifestation of isolation, low sociability of gamers, as well as the narrow focus of their interests. Students-gamers see the negative consequences only in the lack of their personal time.

\section{REFERENCES}

Alisov, E. A., Cherdymova, E. I., Trubina, G. F., Yakushev, A. N., Zhdanov, S. P., Popova, O. V., \& Kobzar-Frolova, M. N. (2018). Study of Dominant Type of Student Ecological Focus. Ekoloji 27(106), 357-362. 
Borytko, N. M. (2002). Leisure in education space. Extracurricular, 6, 15-22.

Buglak, S. S. (2013). The Invasion of computer game language into the reality desert. Media philosophy IX. Languages of media philosophy. St. Petersburg: Publishing house of Russian Christian Humanities Academy.

Cherdymova, E. I., Afanasjeva, S. A., Parkhomenko, A. G., Ponyavina, M. B., Yulova, E. S., Nesmeianova, I. A., \& Skutelnik, O. A. (2018). Student ecological consciousness as determining component of ecological-oriented activity. Eurasian Journal of Biosciences, 12(2), 167-174.

Cherdymova, E. I., Prokopyev, A. I., Karpenkova, T. V., Pravkin, S. A., Ponomareva, N. S., Kanyaeva, O. M., Ryazapova, L. Z., \& Anufriev, A. F. (2019). EcoArt Therapy as a Factor of Students' Environmental Consciousness Development. Ekoloji, 28(107), 687-693.

Cherevko, A. N. (2010). Phenomenon of leisure gaming practices of youth in modern Russia. Sociosphere, 2, 60-64.

Dobrenkov, V. I., \& Kravchenko, A. I. (2001). Sociology. Moscow: Publishing house Infra.

Fomicheva, Yu. V., Shmelev, A. G., \& Burmistrov, I. V. (1991). Psychological correlates of enthusiasm for computer games. MSU Bulletin Psychology, 3, 36-38.

Gutman, I. E. (2009). Computer virtual games: cultural anthropological aspects of analysis: Thesis of PhD. St. Petersburg.

Karpenko, L. A. (2005). Psychological lexicon. Encyclopedic dictionary in six volumes. Moscow: PER SE.

Korbut, A. (2009). Review: V. V. Volkov, O. V. Kharkhordin, the "Theory of practices". Social practices, 1(2), 178-184.

Korneeva, E. (2004). Computer dependence: "Bermuda triangle" around the corner. The world of the family, 13, 26-37.

Parking, S. (2015). The most famous computer games. Moscow: Eksmo.

Pleshakov, V. A., \& Namestnikov, V. V. (2013). Computer games as a factor of cyber socialization of the person in the XXI century. Secondary vocational education, 8, 36-37.

Reznick, Yu. (2008). Human being as social practices. Man yesterday and today: interdisciplinary research. Moscow: IF RAS.

Savchuk, V. V. (2014). Media Philosophy. An attack of reality. - 2nd ed. corrected and supplemented. St. Petersburg: Publishing house of Russian Christian Humanities Academy.

Shapkin, S. (1999). Computer game: a new area of psychological research. Psychological journal, 1, 34-46.

Shlimovich, B. (1998). Computers and children. Science and life, 11, 41-42. https://doi.org/10.1080/05775132.1998.11472042

Shugalsky, S. S. (2012). Social practices: interpretation of concepts. Knowledge. Understanding. Skill, 2, 276-280. 
Sorokoumova, E. A., Cherdymova, E. I., Rezvantseva, M. O., Kochneva, L. V., Latysheva, V. V., \& Perkova, E. P. (2019). Environmental and Social Practices of Old Stuff Use and Disposal by Students. Ekoloji, 28(107), 5065-5069.

Volkov, V. V. (1997). On the concept of practices in social Sciences. Sociological research, 6, 913.

Wittgenstein, L. (1994). Philosophical researches. Philosophical work. Moscow: Nauka.

Zborovsky, G. E. (2007). Daily practices in the lifestyle system. Human life: values of everyday life in socio-cultural programs and practice: Materials of $X$ international scientific-practical conference of the Humanitarian University. Ekaterinburg: Publishing house of Humanities Univ.

Correspondence: Elena I. Cherdymova, PhD in Psychology, Associate Professor of the Department of Sociology and Cultural Studies, Samara National Research University named after Academician S.P. Korolev, Samara, Russia. E-mail: cheiv77@mail.ru 